\title{
A lógica territorial na política de saúde brasileira
}

\author{
The territorial logic in brazilian health policy
}

\author{
Eliane Cristina Lopes Brevilheri \& \\ Argéria Maria Serráglio Narciso a \& \\ Márcia Pastor\&\&\&
}

\begin{abstract}
Resumo:
Este artigo tem por objetivo refletir sobre como a dimensão territorial tem sido abordada na atual política de saúde brasileira. Traz, inicialmente, uma aproximação da discussão teórica sobre a categoria território e suas implicações à política social. Posteriormente, analisa como essa categoria foi incorporada nos princípios e diretrizes do Sistema Único de Saúde - SUS, nos principais programas implantados e nos instrumentos normativos da política de saúde a partir de 1990. Conclui-se que: a dimensão territorial esteve presente desde a concepção do SUS por meio da diretriz de regionalização das ações e serviços. Nos principais programas implantados nos anos 1990, a dimensão territorial teve um caráter de recortes geográficos e os instrumentos normativos deram centralidade ao processo de descentralização. Contudo, a partir dos anos 2000, a estratégia de regionalização, apontando para a perspectiva territorial, ganha maior significado. Entretanto, ainda é preciso ultrapassar a lógica meramente político-administrativa e atuar na perspectiva de identificar as reais necessidades das populações, suas potencialidades, diversidades e particularidades, na direção de "território usado" a que se refere Milton Santos.
\end{abstract}

Palavras-chave: Território. Saúde. Regionalização. Descentralização. Sistema Único de Saúde.

\begin{abstract}
:
This article aims to reflect on the territorial dimension has been addressed in the current Brazilian health policy. Provides an initial approximation of the theoretical discussion about the category territory and its implications for social policy. Then we analyze how this category was included in the principles and guidelines of the National Health System, deployed in key programs and normative instruments of health policy from 1990. It is concluded that: the
\end{abstract}

* Assistente Social da Secretaria de Saúde do Estado do Paraná/18a RS/UCT, doutoranda do Programa de Pós-Graduação em Serviço Social e Política Social da Universidade Estadual de Londrina (UEL). E-mail: amaurieliane@bol.com.br

* Assistente Social do Hospital Universitário de Londrina/AHC, doutoranda do Programa de PósGraduação em Serviço Social e Política Social da Universidade Estadual de Londrina (UEL). E-mail: argeria@sercomtel.com.br

$\therefore$ Assistente Social, doutora em Serviço Social (PUC/SP), docente do curso de serviço social da UEL. Email: marcia.pastor@gmail.com 
territorial dimension was present from conception through SUS guideline regionalization of activities and services. In the main programs implemented in the 1990s, the territorial dimension had a character cutouts geographical and normative instruments gave centrality to the process of decentralization. However, from the 2000s, the regionalization strategy, pointing to the territorial perspective, gains greater significance. However, we still need to overcome the logic purely political-administrative and act so as to identify the real needs of the people, their potential, diversity and particularities, towards "used territory" referred to Milton Santos.

Keywords: Territory. Health. Regionalization. Decentralization. Unified Health System.

\section{Introdução}

O tema território tem sido abordado em diferentes áreas do conhecimento. No Brasil, embora diversos estudiosos venham se dedicando a essa temática, os trabalhos do geógrafo Milton Santos têm sido considerados a principal referência, uma vez que trazem a concepção de território enquanto categoria social pautada em processos sociais. Para esse autor, o território deve ser entendido a partir de sua utilização pela população; é o "território usado", que envolve também a identidade dos que nele vivem. Suas formulações vêm, assim, trazendo grandes contribuições para adensar o debate sobre a compreensão do território e sobre sua utilização.

No âmbito das políticas sociais, o território vem ganhando importância principalmente a partir da promulgação da Constituição Federal de 1988, que promoveu mudanças no que diz respeito à ampliação dos direitos de cidadania e à definição de diretrizes para a sua gestão.

Ao introduzir o princípio da descentralização político-administrativa, a atual Constituição Federal indicou a necessidade de que fosse promovida uma maior distribuição de competências entre união, estados e municípios, em substituição ao centralismo de poder na esfera federal.

A descentralização torna-se uma exigência tendo em vista a dimensão territorial do país e o alto grau de heterogeneidades e desigualdades socioterritorial existentes entre os municípios e regiões. 
Assim, município foi reconhecido como ente federado o que, em tese, significa ser dotado de autonomia, poder de decisão e capacidade administrativa para gerir as políticas sociais, aproximando o Estado do cotidiano da população e, portanto, de seus problemas de vida.

Em relação à saúde, a partir do reordenamento jurídico promovido pela Constituição, há o seu reconhecimento como direito fundamental e a indicação de que as necessidades de saúde são produtos das relações sociais, e dessas com o meio físico, social e cultural. 0 processo saúde doença é, portanto, social, espacial e historicamente determinado.

O direito à saúde deve ser garantido pelo Estado por meio de um sistema único pautado nos princípios fundamentais de universalidade, integralidade e equidade. Em sua organização, precisam ser observadas as diretrizes de regionalização e hierarquização dos serviços, ou seja, deve pautar-se sob uma base territorial seguindo uma lógica de delimitação de áreas de abrangência, considerando os níveis de complexidade das necessidades e da atenção a ser prestada.

A categoria território tem, portanto, feito parte da pauta da agenda da política de saúde como condição indispensável para se alcançar a universalidade de acesso por meio da oferta de serviços o mais próximo possível dos cidadãos.

O presente trabalho tem como objetivo identificar e refletir como essa categoria vem sendo retratada na política de saúde, no contexto do Sistema Único de Saúde (SUS). A fim de fornecer uma base teórica para essa discussão, são realizadas, inicialmente, aproximações conceituais sobre o conceito território e a indicação das implicações para a gestão de políticas sociais. Em seguida, serão apresentados dados e reflexões decorrentes de levantamento sobre como a dimensão territorial foi incorporada na legislação de criação do SUS, nos principais instrumentos normativos da política de saúde brasileira e nos programas implantados a partir dessa nova institucionalidade.

\section{Território: aproximações conceituais e implicações para a gestão de políticas sociais}

Ao longo da história, desenvolveram-se distintos usos e definições sobre território. Na geografia política clássica, que teve Friedrich Ratzel como um dos seus expoentes, o território era compreendido como um espaço delimitado ocupado por um grupo populacional, organizado e controlado pelo Estado. Este último era visto como o único 
detentor do poder e, portanto, como a única instituição que podia intervir sobre o território (FERNANDES, 2009).

Em decorrência das transformações societárias, novos enfoques sobre o conceito de território emergiram, constituindo uma corrente que ficou conhecida como geografia política crítica. O francês Claude Raffestin, por exemplo, foi um dos críticos da tendência clássica. Embora reconhecendo o poder soberano do Estado, defendia a multidimensionalidade do poder, enfatizando a coexistência de outras organizações que também detêm parcelas de poder e que interagem tanto no interior como para fora um território nacional, tais como o mercado econômico, as igrejas etc. (RAFFESTIN, 1993). Portanto, "tal postura resulta em uma abordagem relacional do território, formado por relações de poder multidimensionais" (FERNANDES, 2009, p. 62).

As múltiplas determinações que influenciam historicamente a constituição dos territórios foram abordadas também nos trabalhos do geógrafo brasileiro Milton Santos. Para ele, o território deve ser concebido para além de sua dimensão estritamente geográfica, visto que expressa determinações econômicas, sociais, políticas e culturais. Porém, tais dimensões são vivenciadas de maneira singular pelos grupos de pessoas que habitam um mesmo território e que estabelecem entre si relações e identidades próprias (SANTOS, 2007).

Santos compreende o território como espaço composto por um conjunto integrado de sistemas de objetos (fixos) e de ações (fluxos). Os objetos 'fixos' (ou imóveis) envolve tanto os elementos naturais (rios, montanhas, planícies etc.) como as obras criadas pelo homem (prédios, estradas, barragens, indústrias e outros); ou seja, inclui a natureza e também as ações dos homens já realizadas sobre o espaço: é a história que se apresenta como 'forma'. Entretanto, não se constitui apenas do passado, pois expressa também o sistema de ação que se refere ao presente, ao movimento das pessoas sobre o território, à circulação de mercadorias, às ideias; traduz a dinâmica de diversos atores que disputam interesses e projetos quanto ao uso do território (MONKEN et al., 2008; SILVEIRA, 2009).

Nas palavras de Silveira (2009, p. 129), "o território usado abriga as ações passadas, já cristalizadas nos objetos e normas, e as ações presentes, as que se realizam diante nos nossos olhos". 
Para Santos (2000, p. 96), só tem sentido analisar o território a partir do seu uso, a partir da apropriação que as pessoas fazem do espaço habitado, pois "O território é o chão e mais a população, isto é uma identidade, o fato de pertencer àquilo que nos pertence".

Partindo dessa compreensão da dimensão histórica, pode-se afirmar que, no Brasil, o processo de crescimento econômico tem provocado profundas desigualdades socioterritoriais. Especialmente a partir da segunda metade do século XX, verificou-se o deslocamento de milhões de pessoas das zonas rurais para as áreas urbanas: em 1980, 80\% da população já residiam nos espaços urbanos (NAKANO; KOGA, 2013).

Os intensos fluxos migratórios do rural para o urbano foram decorrentes dos chamados "fatores de expulsão" (SINGER, 1980), ${ }^{1}$ e, impulsionados pelo estímulo ao emprego com a industrialização e pela integração das áreas com a construção de rodovias, contribuindo para a formação de grandes núcleos urbanos.

Longe de garantir melhores condições de urbanização e redução das vulnerabilidades, os avanços do capitalismo periférico, baseado na exploração de trabalhadores, levaram à concentração patrimonial e ao aprofundamento das desigualdades sociais (NAKANO; KOGA, 2013).

Muitas cidades se expandiram com a criação de diferentes bairros. Em recente trabalho, Nakano e Koga (2013) classificaram os bairros em primeiro e segundo tipo. 0 primeiro possui melhores condições urbanísticas, serviços e infraestrutura, sendo em sua maioria composto por grupos com maior poder aquisitivo ou boa capacidade de endividamento, construído com acompanhamento técnico e dentro da legislação urbana e ambiental.

No segundo tipo, há inicialmente a ocupação de locais mais periféricos pelos moradores, que somente depois passam a contar com equipamentos, serviços e infraestrutura urbana; os moradores em sua maioria são aqueles advindos dos fluxos migratórios. Esses bairros, em geral, localizavam-se em loteamentos clandestinos e

\footnotetext{
${ }^{1}$ Paul Singer (1980) realizou diversos estudos sobre os processos de urbanização, industrialização e fluxos migratórios, ocorridos no Brasil, durante a segunda metade do século XX. Segundo o autor, os "fatores de expulsão" estão relacionados à introdução de relações de produções capitalistas acarretando a expulsão de camponeses e não proprietários de terras, visando ao aumento da produtividade e à consequente diminuição de emprego. Outra razão está relacionada aos fatores de estagnação, decorrentes da crescente pressão populacional sobre as áreas cultiváveis e os seus limites, tanto pela insuficiência como pelo monopólio dos grandes proprietários de terras.
} 
irregulares, longe das oportunidades econômicas e sociais, mas constituíam alternativas de moradia para pessoas de baixa renda, que viviam em situações urbanas precárias, devido tanto à ausência de serviços públicos como também à insegurança na posse do imóvel gerada pela irregularidade fundiária, com risco de despejos.

O uso desses espaços urbanos envolve relações complexas e de poder. São campos de disputas de interesses econômicos, políticos e sociais, os quais produzem e reproduzem desigualdades, e esses são grandes desafios na gestão de políticas sociais (NAKANO; KOGA, 2013).

De acordo com Santos (2007, p. 151), "Há desigualdades sociais que são, em primeiro lugar, desigualdades territoriais, porque derivam do lugar onde cada qual se encontra. Seu tratamento não pode ser alheio às realidades territoriais. O cidadão é o indivíduo num lugar".

Por isso, há que se considerar que a configuração socioterritorial de um país de dimensões continentais como o Brasil "pode construir processos emancipatórios, mas pode também atuar na mesquinhez e apartações que provocam erosões nos padrões de civilidade" (KOGA; NAKANO, 2006, p. 98).

Entende-se que o reconhecimento das desigualdades socioterritoriais é condição essencial para a definição e implantação de políticas públicas. Limitar tais políticas às demandas genéricas e/ou a públicos-alvo reduz suas possibilidades de dar respostas concretas às desigualdades existentes nos diferentes territórios e, desse modo, impedem sua efetividade, a democracia e a perspectiva de promover a cidadania (KOGA, 2011). A autora ainda acrescenta: "A vida da população se dá em condições concretas, especializadas, peculiares, nas quais o território e suas condições são determinantes" (KOGA, 2011, p. 20).

Portanto, no planejamento de ações governamentais,

Trata-se de trazer a dimensão territorial para o processo de gestão descentralizada e participativa, no qual o papel dos municípios se torna elemento crucial para seu funcionamento em territórios locais onde se materializam as condições de vida individuais e coletivas (NAKANO; KOGA, 2013, p. 158). 
Na continuidade deste estudo, pretende-se indicar como a categoria território vem sendo incorporada na estruturação da atual política de saúde no Brasil, definida a partir do último processo constituinte.

\section{Política de saúde e território}

A concepção de território, advinda da geografia crítica, teve grande influência nos estudos sobre saúde no Brasil desde o final da década de 1970, sobretudo no campo da epidemiologia.

Com o processo de urbanização e a consequente intensificação das relações sociais, ocorreram mudanças no perfil epidemiológico da população, e as abordagens tradicionais, baseadas em análises unicausais, já não eram suficientes para a compreensão do processo saúde-doença. Especialmente sob a influência dos trabalhos de Milton Santos, a epidemiologia incorpora a categoria território aos debates e análises, possibilitando a compreensão da historicidade do processo biológico e dos fatores econômicos, políticos, sociais e culturais como determinantes e condicionantes do processo saúde-doença (FARIA; BORTOLOZZI, 2009).

Nessa perspectiva, ganhou significado a compreensão de que o território "só se torna um conceito utilizável para a análise social, quando o consideramos a partir de seu uso, a partir do momento em que o pensamos juntamente com aqueles atores que dele necessitam" (SANTOS, 2000, p. 22).

É importante resgatar que, antes da Constituição de 1988 , as políticas sociais brasileiras não contemplavam a concepção ampliada de direitos sociais. As primeiras iniciativas de proteção social datam de 1930 e se caracterizam como um modelo corporativista e restritivo, por ser atrelado aos direitos trabalhistas dos setores economicamente mais importantes no período (portuários, ferroviários etc.). Muito lentamente, esse modelo foi estendido a outras categorias profissionais. Somente na década de 1970, ainda durante o regime militar, ocorreu a inclusão dos trabalhadores rurais no sistema previdenciário brasileiro. As políticas de saúde, nesse período, tinham estreita relação com as atividades previdenciárias e estavam voltadas aos segmentos da população inseridos no mercado formal de trabalho. 
No final nos anos 1970, no bojo da mobilização da sociedade brasileira por democracia e direitos sociais, o setor saúde contou com o sólido Movimento pela Reforma Sanitária, que envolveu intelectuais, profissionais de saúde, organizações populares e sindicais. Tal Movimento tinha como propósito a luta pela garantia da saúde como direito universal e pela construção de um sistema único e estatal nessa área.

O Sistema Nacional de Saúde (SNS) organizado em 1975 se caracterizava por forte centralização na esfera federal, cujas competências eram dicotomizadas entre o Ministério da Saúde e o Ministério da Previdência e Assistência Social, cabendo ao primeiro as ações coletivas e ao segundo as ações individuais. Isso contribuía para a inexistência de um comando único na política de saúde (ANDRADE; PONTES; MARTINS JUNIOR, 2000).

Diante das contestações do Movimento pela Reforma Sanitária ao modelo de saúde vigente, aliado às tendências mundiais e às orientações de organismos internacionais, já no início dos anos 1980, o governo brasileiro criou programas na área de saúde, tais como: - Programa Nacional de Serviços Básicos de Saúde (PREVSaúde), a partir de uma coordenação interministerial a fim de estender a cobertura dos serviços de saúde; e o Programa de Ações Integradas de Saúde (PAIS), que tinha como um de seus principais objetivos a potencialização e priorização dos serviços de atenção primária à saúde, com ênfase na prevenção, realizado por meio de convênios entre as três esferas de governo, a fim de organizar serviços básicos nos municípios (GIOVANELLA; MENDONÇA, 2008).

Apesar disso, o grande marco do Movimento pela Reforma Sanitária foi VIII Conferência Nacional de Saúde realizada em 1986. Partindo do consenso de que para o setor saúde não seriam suficientes reformas administrativas e financeiras, mas, sobretudo, mudanças em todo o arcabouço jurídico-institucional, foram definidas estratégias a serem defendidas no processo constituinte. Dentre essas, destacam-se a defesa da criação de um sistema único de acesso universal, igualitário, com uma rede de serviços de saúde descentralizada, regionalizada e hierarquizada de saúde, contando com a participação popular e com a valorização do primeiro nível de atenção, pautado em um conceito ampliado de saúde.

Tais estratégias foram definidas a partir de um diagnóstico realizado pelo Movimento ao longo dos anos 1970 e 1980 e que resultaram em quatro considerações em relação às ações e serviços prestados à população pelo setor. Estas ações demonstravam a 
distribuição desigual dos recursos da saúde no território brasileiro e que reproduziam as desigualdades sociais e econômicas do país. As referidas considerações foram descritas por Gondim et al. (2008) da seguinte forma: desintegração das unidades de saúde, com sobreoferta de serviços em alguns lugares e ausência em outros; excessiva centralização, implicando por vezes impropriedades das decisões, pela distância dos locais onde ocorrem os problemas; baixa cobertura assistencial, com segmentos populacionais excluídos do atendimento, especialmente os mais pobres e nas regiões mais carentes; irresolutividade, desperdício e fragmentação das ações e serviços no enfrentamento aos problemas e necessidades apontadas nas diferentes regiões e populações brasileiras.

\section{A dimensão territorial presente na construção do SUS}

Com base no diagnóstico realizado pelo Movimento pela Reforma Sanitária e nas proposições defendidas no processo constituinte, foram definidas as bases legais para a criação do Sistema Único de Saúde (SUS), conforme disposto no texto constitucional e nas leis orgânicas da saúde - Leis 8.080 e 8.142, ambas de 1990. Há o reconhecimento da saúde como direito fundamental e a incorporação de novas dimensões para a compreensão do processo saúde-doença ao apontar os fatores determinantes e condicionantes como: a alimentação, a moradia, o saneamento básico, o meio ambiente, o transporte, o acesso a bens e serviços e outros. Indicaram ainda que o direito à saúde deveria ser garantido pelo Estado, pautado nos princípios de universalidade, integralidade e equidade. Estes últimos são denominados de princípios doutrinários do SUS (BRASIL, 1988; 1990).

O princípio da universalidade trata da mudança fundamental prevista no SUS, que é a que garante a todos os brasileiros o direito à saúde. Isso pressupõe a extensão da cobertura dos serviços de saúde de maneira que possam ser acessados por toda a população. Significa não somente a ampliação da quantidade de serviços, mas também sua localização mais próxima dos que deles necessitam, além de sua capacidade resolutiva.

A integralidade diz respeito à existência de ações de promoção à saúde, da prevenção de riscos e agravos e de assistência e recuperação, ou seja, desde ações preventivas até o diagnóstico, tratamento e reabilitação. Isso implica a oferta de serviços necessários aos indivíduos e à coletividade, por meio da articulação entre diversos serviços 
de saúde que podem estar instalados em diferentes locais, desde que acessíveis à população.

O princípio da integralidade está associado à ideia de uma rede de serviços de saúde que extrapola o âmbito de um município exigindo, portanto, que haja relações entre os entes federados que, embora autônomos, devem ser interdependentes na prestação de serviços de saúde (SANTOS; ANDRADE, 2013).

A equidade pressupõe o tratamento de forma desigual os desiguais, a fim de alcançar a igualdade. Esse é um princípio que visa garantir a justiça social indicando que os maiores investimentos devem dar-se nos lugares onde as necessidades forem maiores.

Além dos princípios doutrinários, foram também definidas as diretrizes organizativas e operacionais dos serviços ofertados no âmbito Sistema Único de Saúde (SUS), quais sejam: a descentralização, a regionalização, a hierarquização e a participação da comunidade (BRASIL, 1988; 1990).

A ideia de descentralização político-administrativa se justifica, especialmente, se considerada a dimensão do território brasileiro, que assume proporções continentais, além da enorme desigualdade existente entre as diferentes regiões.

No âmbito da gestão do sistema de saúde, isto implica na partilha de poder de decisão do nível central para os estados e municípios, com a definição de competências político-administrativas pelo sistema por cada um dos entes federados, incluindo o remanejamento dos recursos necessários para o financiamento das ações.

A descentralização traz também a ideia de avanço democrático e de novas relações entre Estado e sociedade civil, uma vez que o sistema deve ser gerido com ampla participação da comunidade, proporcionando o exercício do controle social por meio de mecanismos institucionais de democracia participativa, tais como os conselhos e conferências de saúde.

A diretriz regionalização pressupõe a necessidade de delimitação de uma base territorial, levando em conta a divisão político-administrativa do país e outras subdivisões adotadas na organização das ações.

Na execução das ações do sistema, além de regionalizados, os serviços deveriam ser organizados de forma hierarquizada segundo o grau de complexidade, levando em conta 
os tipos de serviços que produzem e a complexidade tecnológica necessária à realização das ações (BRASIL, 1990).

Isso implica o estabelecimento de uma rede que articula as unidades mais simples às mais complexas por meio de um sistema de referência, contrarreferência e informações, ou seja, uma integração dos diferentes níveis de complexidade como forma de garantir a integralidade.

Os níveis de complexidade dos serviços ofertados à população foram assim definidos: primário, secundário e terciário, ou, ainda, atenção básica, de média e alta complexidade, considerando a densidade tecnológica de cada serviço e não o grau de importância. Tratase de uma forma de organizar os serviços a fim de atender às diferentes necessidades dos cidadãos.

Juntas, as diretrizes de regionalização e hierarquização pressupõem a necessidade de que o Estado brasileiro promova a articulação e integração de um conjunto de ações e serviços de diferentes níveis de complexidade e situados em diversos territórios políticoadministrativos, de modo a garantir o acesso ao cidadão e a atender as suas necessidades de saúde.

Ao definir o SUS como um sistema regionalizado e hierarquizado, estabeleceu-se um modelo de atenção à saúde e sua forma de organização e gestão, indicando a necessidade de romper com a visão - historicamente presente no campo da saúde - como um processo eminentemente biológico, desvinculado de fatores econômicos, sociais, políticos e culturais e, ainda, do lugar onde se vive. Essa análise foi realizada por Faria e Bortolozzi (2009, p. 35), ao afirmarem que: “Ao entender o espaço no contexto do desenvolvimento técnico-científico-informacional o setor saúde passa a entender a doença não apenas como o resultado da presença de vírus e bactérias (análise unicausal), mas, como resultado de uma dinâmica social complexa".

A análise dos princípios e diretrizes do Sistema Único de Saúde permite a constatação, por diferentes estudiosos, a exemplo de Barcellos (2008), da existência de uma forte relação com a definição de território.

Nesta mesma direção, Gadelha et al. (2011) afirmam que houve, já na concepção do SUS, uma associação entre a perspectiva territorial e a diretriz de descentralização, por meio da estratégia de regionalização das ações e serviços de saúde, ou seja, a 
regionalização orienta a descentralização com o objetivo de garantir a extensão da cobertura e a universalidade da atenção, levando em consideração a diversidade existente no país. Visa garantir o direito à saúde, reduzindo as desigualdades sociais e territoriais.

Contudo, há que se considerar que a criação do SUS ocorre em um cenário em que as teses neoliberais ganham força no Brasil. No início da década de 1990, o país se insere em um processo de ajustes e reformas voltadas à redução da intervenção do Estado no que diz respeito às políticas sociais. Dentre os aspectos mais relevantes do ideário neoliberal destacam-se: o predomínio do individualismo; o bem-estar individual sobrepondo-se ao coletivo; predomínio da liberdade e da competitividade; naturalização da miséria; manutenção de um Estado mínimo. Conforme aponta Behring (2003, p. 64), as medidas adotadas permitiram visualizar o Estado brasileiro como "um estado mínimo para os trabalhadores e máximo para o capital".

Assim como as demais políticas sociais, não obstante as conquistas no campo legal, a saúde foi atingida pelo cenário de mudanças decorrentes do novo padrão de acumulação capitalista.

\section{A dimensão territorial presente nos instrumentos normativos e programas}

O início dos anos 1990 é marcado pelo processo de descentralização do setor saúde no Brasil, tornando a esfera municipal o principal responsável pela gestão dos serviços de saúde e pela prestação direta de grande parte das ações e serviços.

No processo de implantação do SUS, a descentralização ganhou centralidade dentre as estratégias, especialmente na perspectiva de responsabilização dos municípios pela provisão dos serviços e organização de sistemas municipais de saúde (VIANA et al., 2008). Isso pode ser observado no conteúdo das quatro primeiras Normas Operacionais Básicas (NOB'S), ${ }^{2}$ editadas respectivamente em 1991, 1992, 1993 e 1996, conforme demonstrada a seguir.

A NOB 01/91 reproduz grande parte dos elementos que compõem as Leis Orgânicas da Saúde, uma vez que elas constituem as bases de implantação e operacionalização do SUS e seu enfoque esteve direcionado à questão dos mecanismos de repasse de recursos

\footnotetext{
2 As Normas Operacionais Básicas são instrumentos formulados para disciplinar o processo de implementação do SUS, definindo estratégias que orientam a operacionalidade do sistema.
} 
financeiros do INAMPS (Instituto Nacional de Assistência Médica e Previdência Social) para os estados e municípios e que representaram fator de incentivo ao processo de descentralização (BRASIL, 1991).

A norma editada em 1992 não trouxe novidades em relação a anterior. A NOB/93 define formas de gerenciamento do processo de descentralização nas três esferas de governo, com a criação das Comissões Intergestores Tripartite (com representação da união, estados e municípios), as Comissões Intergestores Bipartite (estados e municípios) e dos Conselhos Municipais. Além disso, criou níveis de gestão para os municípios (Incipiente, Parcial e Semiplena) e estados (Parcial e Semiplena). Portanto, o que houve foi a incorporação de elementos relacionados ao processo de descentralização, tendo como foco a municipalização.

Na NOB/96, a Atenção Básica foi caracterizada como primeiro nível de atenção. Instituiu, ainda, uma nova modalidade de transferência de recursos financeiros do governo federal para os municípios (até então realizada com base em convênios e no pagamento por produção de serviços), por meio dos Pisos de Atenção Básica. Foi enfatizado o processo de municipalização dos serviços, por meio dos sistemas municipais de saúde.

Essas foram, portanto, as principais características das NOB's editadas na década de 1990. Nesse mesmo período, dois importantes programas foram lançados pelo governo federal.

Em 1991, o então presidente Fernando Collor, por meio da Fundação Nacional de Saúde (FNS), lança o Programa Nacional de Agentes comunitários de Saúde (PNACS), tendo como referência a experiência desenvolvida no Estado do Ceará, desde 1987.

O Programa foi criado para atuar, inicialmente, em áreas onde houvesse dificuldades de interiorização das ações de assistência médica, a exemplo das Regiões Norte e Nordeste. Contudo, estendeu-se às demais regiões e municípios brasileiros, com o objetivo de oferecer assistência voltada às famílias, de acordo com a realidade e os problemas de cada comunidade. Sua implantação constituiu uma primeira estratégia para a mudança no modelo assistencial no âmbito dos municípios mediante a organização da atenção básica no nível local. 
Aos Agentes Comunitários de Saúde (ACS) cabia o cadastramento de um número de famílias adscritas ${ }^{3}$ (em torno de 150 famílias ou 750 pessoas) a uma base geográfica aos seus cuidados, com prioridades àqueles que apresentassem maiores riscos de adoecer e morrer.

Para Giovanella e Mendonça (2008), a criação do PACS teve um caráter emergencial, focalizado, com elenco restrito de ações. As autoras ainda destacam que se deu também como forma de atender às demandas políticas apresentadas pelas secretarias municipais de saúde, que desejam apoio financeiro do governo federal para a operacionalização dos serviços da rede básica de saúde.

Em 1994, a fim de contribuir para a reorganização do nível de atenção primária, ou seja, colaborar na organização do SUS em seu processo de municipalização, foi implantado o Programa Saúde da Família (PSF), mais tarde transformado em Estratégia Saúde da Família (ESF), em caráter substitutivo e complementar ao PACS.

O PSF consistiu uma estratégia para reverter o modelo de atenção vigente, promovendo a integração das atividades nos territórios determinados a fim de propiciar o enfrentamento dos problemas identificados. Para sua operacionalização contava com equipes multiprofissionais compostas por médicos, enfermeiros, auxiliares de enfermagem e agentes comunitários de saúde, como referência para a população de no máximo 1.000 famílias (ou 4.550 pessoas). Para Gondim et al. (2008, p. 247), “A menor unidade espacial da base territorial do sistema de saúde é este território - a área de abrangência das famílias adscritas a cada unidade básica".

Pode-se observar que expressões como "adscrição da clientela" e "área de abrangência" da atuação das equipes são tomadas como diretrizes do programa e indicam a definição de territórios. Além disso, a territorialização é apontada como estratégia metodológica para o conhecimento das condições de vida e saúde da população de determinada área.

Fazendo a análise desse programa, Monken e Barcellos (2007) reconhecem a evidente intenção de demarcar, delimitar territórios como forma de regular e normatizar

\footnotetext{
3 “Na adscrição de clientela, a unidade atende somente a população residente em determinada área territorial. Para isso, delimita-se uma área geográfica de abrangência da unidade de saúde; os residentes da área são cadastrados pela unidade, e a unidade é de uso exclusivo desses moradores" (GIOVANELLA; MENDONÇA, 2008, p. 584).
} 
a atuação das equipes. Contudo, afirmam que "a adoção de um limite para atuar, por exemplo, sobre as condições ambientais e de saúde é reconhecidamente artificial. Nem o ambiente pode ser completamente constrito dentro de um território, nem os processos sociais se restringem a esses limites" (MONKEN; BARCELLOS, 2007, p. 186).

No processo de municipalização da saúde, podem ser identificados diferentes tipos de território, os quais foram sistematizados por Mendes (1993) como: território-distrito, território-área, território-microárea e território moradia.

O território-distrito diz respeito à delimitação político-administrativa, correspondendo a uma determinada coordenação sanitária (município, conjunto de municípios, subdivisões municipais etc.). O território-área, primeira subdivisão do território-distrito, diz respeito à delimitação da área de abrangência de uma unidade de saúde. O território-microárea, seria a delimitação que parte da suposta homogeneidade socioeconômica e sanitária - área de atuação dos ACS, e o território-moradia consistiria no espaço de menor agregação social, ou seja, de moradia da família ou de um grupo de indivíduos.

Portanto, pode-se observar que, no âmbito desses programas (PACS e PSF/ESF), a dimensão territorial teve esse caráter, particular, de recortes geográficos a fim de definir as áreas de atuação das equipes, considerando o número de famílias a serem atendidas.

Se as NOB's e os programas implantados nos anos 1990 deram centralidade ao processo de descentralização, a estratégia de regionalização, indicando a perspectiva territorial, aparece com força nas normatizações e ganha maior significado a partir dos anos 2000, especialmente, com a publicação da Norma Operacional de Atenção a Saúde (NOAS 01/2001) (BRASIL, 2001).

Considerando que o processo de municipalização havia promovido a atomização dos serviços, a NOAS aponta a regionalização da assistência à saúde como forma de reorganizar o sistema. Propôs a criação de polos de atenção que detivessem maior capacidade de dar respostas aos problemas e necessidades de saúde no âmbito das regiões, extrapolando, portanto, o território dos municípios, orientado pela diretriz de regionalização e hierarquização. Isso implicou a retomada do poder pelo Estado que passou a ser o mediador das relações intermunicipais, tendo como instrumento a Programação Pactuada Integrada (PPI) e a Comissão Intergestores Bipartite (CIB) (GONDIM et al., 2008). 
Na parte introdutória dessa Norma há a indicação da necessidade de aprofundar o processo de descentralização, propondo priorização à regionalização para a organização dos sistemas de saúde. Assim, dedica o primeiro capítulo à diretriz de regionalização apontando conceitos-chave a serem observados no Plano Diretor de Regionalização (PDR), ${ }^{4}$ a exemplo das Regiões de Saúde, definida como:

[...] base territorial de planejamento da atenção à saúde, não necessariamente coincidente com a divisão administrativa do estado, a ser definida pela Secretaria Estadual de Saúde, de acordo com as especificidades e estratégias de regionalização da saúde em cada estado, considerando as características demográficas, socioeconômicas, geográficas, sanitárias, epidemiológicas, oferta de serviços, relações entre municípios, entre outras (BRASIL, 2001).

O processo de elaboração do PDR, sob a coordenação das Secretarias Estaduais de Saúde, deveria envolver um conjunto de municípios de uma determinada região para o planejamento das ações serviços e o estabelecimento de pactos intergovernamentais capazes de garantir níveis adequados de atenção às necessidades de saúde da população daquela extensão territorial.

A NOAS indica também os arranjos interregionais, os quais se organizam em macrorregiões, como forma de garantir a complementariedade de atenção à saúde quando a região não tiver capacidade de dar resposta à complexidade das necessidades da população, especialmente no que diz respeito aos serviços média e alta complexidade. Outros arranjos ainda são possíveis no desenho das regiões: intramunicipais, no caso de municípios com grande extensão territorial; interestaduais e fronteiriças. Neste último, a região de saúde será constituída por municípios limítrofes com países vizinhos (MONKEN; BARCELLOS, 2007).

Contudo, apesar de ter introduzido a definição de regiões de saúde e de instrumentos de planejamento regional, a NOAS recebeu críticas por dificultar a criação dessas regiões de forma mais coerente com a realidade dos lugares dado o seu conteúdo estritamente técnico e normativo e pela forma rígida como os módulos assistenciais foram propostos. Esse fato criou dificuldades para que o sistema de saúde fosse pensado a partir

\footnotetext{
${ }^{4}$ Instrumento de ordenamento do processo de regionalização da assistência em cada estado e no Distrito Federal, baseado nos objetivos de definição de prioridades de intervenção coerentes com as necessidades de saúde da população e garantia de acesso dos cidadãos a todos os níveis de atenção (BRASIL, 2001).
} 
do funcionamento do território na perspectiva de "território usado", onde efetivamente acontecem as pactuações sobre a gestão do sistema (ALBUQUERQUE; IOZZI, 2008).

Tais críticas e debates em relação à NOAS/2001 tiveram papel fundamental e contribuíram, significativamente, na formulação dos conteúdos do Pacto pela Saúde em $2006,{ }^{5}$ como resultado de um processo de discussão, iniciado em 2003 , sobre a necessidade de elaboração de diretrizes para a pactuação de questões fundamentais no processo de gestão do SUS.

O Pacto pela Saúde articula três componentes: o Pacto pela Vida, o Pacto em defesa do SUS e o Pacto de Gestão do SUS. Considerando os objetivos deste estudo, será abordado somente este último, que foi o que estabeleceu responsabilidades entre os entes federados a fim de fortalecer a gestão compartilhada e solidária do SUS (BRASIL, 2006).

O Pacto de Gestão parte da grande constatação de que:

[...] o Brasil é um país continental e com muitas diferenças e iniqüidades regionais. Mais do que definir diretrizes nacionais é necessário avançar na regionalização e descentralização do SUS, a partir de uma unidade de princípios e uma diversidade operativa que respeite as singularidades regionais (BRASIL, 2006).

O texto do Pacto traz a ideia que, embora o SUS seja único em todo o território nacional, há enormes diferenças entre os lugares, de que as pessoas vivem de maneira diferente e em condições diferentes. Portanto, conhecer o lugar onde as pessoas vivem permite uma maior aproximação da realidade.

A esse respeito, Monken e Barcellos (2007, p. 181) afirmam que:

[...] a doença é uma manifestação do indivíduo e a situação de saúde é uma manifestação do lugar, pois os lugares e seus diversos contextos sociais, dentro de uma cidade ou região, são resultados de uma acumulação de situações históricas, ambientais, sociais, que promovem condições particulares para a produção de doenças.

Nessa perspectiva, a análise territorial deverá contemplar, dentre outros aspectos, a coleta de dados do espaço geográfico, a identificação e localização de objetos, os usos

\footnotetext{
${ }^{5}$ Aprovado pelos gestores do SUS na reunião da Comissão Intergestores Tripartite do dia 26 de janeiro de 2006 e divulgado por meio da Portaria no. 399/GM de 22 de fevereiro de 2006.
} 
destes pela população, os fluxos de matérias e de pessoas, os hábitos, costumes e valores e as inter-relações espaciais.

O Pacto de Gestão traz, também, uma nova definição de regiões de saúde, descritas como "[...] recortes territoriais inseridos em um espaço geográfico contínuo, identificadas pelos gestores municipais e estaduais a partir de identidades culturais, econômicas e sociais, de redes de comunicação e infra-estrutura de transportes compartilhados do território" (BRASIL, 2006).

Tal definição avança em relação à trazida na NOAS/2001, ao inserir os gestores municipais na delimitação das regiões e, ainda, considerar as identidades culturais como características a serem observadas nesse processo.

As regiões de saúde podem ter diferentes desenhos, e suas delimitações não deve ser restrita somente a um processo administrativo, deve sim considerar as diversidades locais, os fatores envolvidos, viabilizando dessa forma o desenvolvimento de uma “regionalização viva” (ALBUQUERQUE; IOZZI, 2008).

O reconhecimento e a apropriação dos espaços locais, pelos gestores, para a intervenção no processo saúde/doença, expressam-se por meio dos dados demográficos e epidemiológicos, pelas dinâmicas das redes de transporte e comunicação, pelos equipamentos sociais existentes, pelos fluxos assistenciais utilizados pela população, mediante discursos das lideranças locais e também por outros dados como o próprio contexto histórico e cultural da região (BRASIL, 2007).

Para Viana et al. (2008, p. 96),

\footnotetext{
Pode-se presumir que o Pacto pela Saúde inicia um novo ciclo de descentralização do SUS ao procurar garantir a função da regionalização de trazer os conteúdos do território para dentro das lógicas de sistema e de descentralização, como forma de pensar e buscar maior coerência e aproximação entre essas duas lógicas.
}

Analisando a concepção de território presente no Pacto pela Saúde e que está associada à regionalização, Gadelha et al. (2009) observam que estão implícitos dois pressupostos básicos: o primeiro é o de garantir maior acesso da população aos serviços, de forma melhor e mais rápida. O segundo relaciona-se à otimização dos gastos, na medida em que as ações e serviços são organizados numa lógica hierárquica, permitindo uma articulação entre aqueles ofertados no nível local e os de maior complexidade. Portanto, 
expressa uma concepção de território como área geográfica delimitada na qual uma população está referida.

Outro instrumento que trouxe à tona a discussão da dimensão territorial na saúde foi a Portaria 4279/2010 do Ministério da Saúde, que estabeleceu diretrizes para a organização da Rede de Atenção à Saúde (RAS) no âmbito do SUS.

A proposta das RAS é resultado de uma análise do cenário da organização da atenção e da gestão do SUS, em que se constatou que, além da fragmentação das ações, vinha ocorrendo uma mudança no perfil epidemiológico brasileiro (que apontava para uma tripla carga de doenças com predominância das condições crônicas) e que ainda se adotava um modelo voltado para a atenção às condições agudas (BRASIL, 2010).

Nesse novo modelo, a Atenção Primária é concebida como eixo estruturante da RAS, situada como a coordenadora do cuidado e ordenadora da rede. A estrutura hierarquizada por níveis de complexidade crescente (primária, secundária e terciária), que apresentava uma tendência a situar a atenção primária como um nível menos complexo, é substituído por uma forma organizacional poliárquica.

Nessa forma de redes, a APS tem um papel estruturante, considerando que não há hierarquização entre os pontos de atenção e que estes se distinguem pela densidade tecnológica que utilizam (BRASIL, 2010; MENDES, 2011).

Dentre os atributos das RAS (ou elementos constitutivos), estão a população e o território, que devem ser definidos a partir de um amplo conhecimento das necessidades e preferências a fim de determinar a oferta de serviços de saúde. Outros elementos apontam para a necessidade de: realização de diagnóstico situacional; identificação das necessidades de serviços de atenção primária e dos demais níveis de atenção e, de serviços de apoio; criação de sistemas logísticos de suporte; e criação de sistemas de regulação e governança da rede (MENDES, 2011; SILVA, 2013).

Tratando dos requisitos para a constituição da RAS, Silva (2013) alerta para a necessária flexibilidade das normativas, especialmente considerando as diferentes realidades econômicas, culturais e sanitárias existentes no país e do próprio caráter processual de construção do SUS. 
Isso se justifica principalmente se considerado que, em momentos anteriores, a exemplo da NOAS/2001, a rigidez técnica e normativa acabou por criar dificuldades para a criação das Regiões de Saúde coerente com a realidade dos lugares.

Ainda se tratando das RAS, Mendes (2011) enfatiza a necessidade de construção de territórios sanitários na organização de redes de atenção em modelos de sistemas de saúde como o SUS, que são pautados na cooperação gerenciada. Para ele, existem, ao menos, duas concepções de territórios sanitários que se aplicam na construção das redes de atenção em saúde:

\begin{abstract}
A primeira toma-os de forma naturalizada como um espaço físico que está dado e está completo; nesta concepção são exclusivamente os critérios geográficos que definem este território-solo. A segunda, coerente com o conceito de espaçopopulação, vê o território como um processo em permanente construção, produto da dinâmica social onde se relacionam sujeitos sociais situados na arena sanitária. Esta última concepção implica que o território sanitário, além de um território geográfico é, ademais, território cultural, social e político (MENDES, 2011, p. 176-177).
\end{abstract}

Para esse autor, há diferenças fundamentais entre territórios sanitários e territórios político-administrativos. Os primeiros "são territórios recortados pelos fluxos e contrafluxos da população de responsabilidade de uma RAS, em suas demandas pelos serviços de saúde", ou seja, são definidos pelos fluxos sanitários de populações em busca da atenção. De forma diferente, os territórios político-administrativos "são territórios de desconcentração dos entes públicos que se definem a partir de uma lógica eminentemente política" (MENDES, 2011, p. 177).

Por fim, é preciso destacar que, após 21 anos da promulgação da Lei que institui o SUS, houve sua regulamentação por meio do Decreto 7.508, de 28 de junho de 2011, com vistas ao enfrentamento de alguns dos obstáculos para a gestão do sistema. Traz, portanto, disposições sobre a organização do SUS, o planejamento e a assistência à saúde, além da articulação interfederativa. Nele são reafirmados os princípios de universalidade, integralidade, equidade, por meio de ações regionalizadas e hierarquizadas.

De acordo com o decreto, a organização do SUS se dará por meio da instituição de regiões de saúde, tendo em vista a provisão dos serviços. Foram incorporados novos elementos à compreensão de regiões de saúde, neste momento, definidas como: 
O espaço geográfico contínuo constituído por agrupamentos de municípios limítrofes, delimitado a partir de identidades culturais, econômicas e sociais e de rede de comunicação e infraestrutura de transportes compartilhados, com a finalidade de integrar a organização, o planejamento e a execução de ações e serviços de saúde (BRASIL, 2011).

Fazendo a análise do texto do decreto, Santos e Andrade (2013, p. 59) destacam que, para além do agrupamento de municípios limítrofes, a região de saúde deve estar "cercada por outros elementos, como a execução e o planejamento [destaque dos autores] de funções comuns, as identidades e as possibilidades de comunicação entre eles".

O levantamento aqui apresentado demonstra como a dimensão territorial foi abordada e incorporada na construção e no processo de implantação do SUS. Os documentos analisados expressam a tentativa de definir o processo de gestão em saúde orientado para o desenvolvimento de ações em territórios onde se materializam as condições de vida da população, visando contribuir para a efetivação dos princípios e diretrizes que orientam a atual política de saúde brasileira.

\section{Conclusões}

No Brasil, o processo de crescimento econômico tem provocado profundas desigualdades socioterritoriais. A utilização dos espaços urbanos tem sido campo de disputas de interesses econômicos, políticos e sociais, os quais produzem e reproduzem desigualdades, sendo um dos grandes desafios na gestão de políticas sociais.

Partindo de diferentes autores - influenciados, em sua maioria, pela concepção de território formulada pelo geógrafo Milton Santos - buscamos trazer referências que se aproximassem da discussão sobre território enquanto categoria social pautada em processos sociais e sua aproximação com a política de saúde brasileira.

A política pública de saúde brasileira foi protagonista no reconhecimento da dimensão territorial para o processo de gestão descentralizada. Nos textos legais e normativos, a questão espacial e territorial tem sido enfocada tanto no que diz respeito à espacialização da doença como na própria organização do sistema de saúde. A ideia de território esteve presente no processo de criação do SUS, a fim de que a definição das ações, para ter resolutividade, deveria considerar as especificidades de cada local. 
Pode-se constatar que a concepção de território adotada nos programas implantados, especialmente nos anos 1990, tinha como referência a definição que o compreende como uma área geográfica delimitada, com uma população adscrita, não considerando a dinâmica dos territórios (sociais, identitárias, culturais) e os condicionantes estruturais e conjunturais que produzem as desigualdades sociais.

Contudo, desde o início dos anos 2000, os documentos oficiais (leis, portarias e decretos) vêm trazendo em seus conteúdos indicações que permitem compreendê-lo como "território usado". Percebemos que houve um avanço nas normatizações legais acerca da concepção territorial, notadamente após o Pacto pela Saúde de 2006, a partir da regionalização.

Mais recentemente, com o Decreto 7.508/2011 (BRASIL, 2011) que definiu as regiões de saúde, o espaço geográfico passou a ser considerado com as suas identidades culturais, econômicas e sociais e a rede de comunicação. Incorporou-se na análise territorial o componente cultural, visto que o território carrega consigo a dimensão simbólica, o que traz possibilidades para as análises na área da saúde, particularmente para a atenção básica.

Apesar de todos os avanços da legislação do SUS em relação à dimensão territorial, ainda há limites que restringem a prática cotidiana aos aspectos administrativos, expressando uma área geográfica delimitada na qual uma população está referida.

É preciso ultrapassar a lógica político-administrativa e atuar na perspectiva de identificar as reais necessidades das populações, suas potencialidades, diversidades e particularidades. Esse é um dos grandes desafios para as políticas socais e, neste caso, da política de saúde, na perspectiva da democratização, proteção e redução das desigualdades socioterritoriais.

Há que pensar, ainda, a gestão de ações articuladas entre as políticas que atuam diretamente no mesmo local, orientando as configurações territoriais em direção a uma melhor qualidade de vida. Trata-se, portanto, de desenvolver ações intersetoriais em territórios onde se materializam as condições de vida, de modo a reduzir as vulnerabilidades individuais e coletivas que afetam a vida das pessoas.

Um dos grandes desafios no SUS é a implementação de ações a partir das necessidades dos territórios. Entender as relações, considerar as diferentes funções e os 
usos espaciais possibilita delimitar territorialmente os espaços para o desenvolvimento de ações de saúde. Uma das exigências para o aprimoramento da gestão é o reconhecimento de que dentro das próprias regiões, microrregiões, ou outros recortes geográficos que sejam adotados, há heterogeneidades, tanto econômicas quanto sociais e culturais.

Considerar as diferenças e desigualdades socioterritoriais das cidades brasileiras pode contribuir com o avanço de estratégias de ação da política de saúde para além do atendimento das demandas setorizadas. As ações no território devem considerá-lo como espaço concreto, em permanente construção, como um campo geossocial dinâmico, onde se criam formas de atendimento dos indivíduos e grupos sociais.

As políticas de saúde devem fundamentar-se nas particularidades dos processos do território usado; isso é fundamental na compreensão do processo saúde-doença para além dos aspectos meramente biológicos e para a organização da atenção à saúde tendo em vista os princípios de universalidade, integralidade e equidade.

\section{Referências}

ALBUQUERQUE, M. V.; IOZZI, F. L. Novos Rumos da regionalização em saúde: o complexo regional da saúde do estado de São Paulo/Brasil. 2008. Disponível em:

<observasaude.fundap.sp.gov.br>. Acesso em: 25 fev. 2013.

ANDRADE, L. O. M.; PONTES, R. J. S.; MARTINS JUNIOR, T. A descentralização no marco da Reforma Sanitária no Brasil. Revista Panamericana de Salud Pública, Washington, v. 8, n. 12, jul./ago. 2000. Disponível em:

<http://www.scielosp.org/scielo.php?script=sci_arttext\&pid= S1020-

49892000000700026>. Acesso em: 8 ago. 2012.

BARCELLOS, C. Problemas emergentes de saúde coletiva e a revalorização do espaço geográfico. In: (Org.). Território ambiente e saúde. Rio de Janeiro: FIOCRUZ, 2008. p. 43-57.

BEHRING, E. Brasil em contra-reforma: desestruturação do Estado e perda de direitos. São Paulo: Cortez, 2003.

BRASIL. Constituição (1988). Constituição da República Federativa do Brasil. Senado Federal: Centro Gráfico, Brasília, 1988.

Lei $n$ - 8.080, de setembro de 1990. Dispõe sobre as condições para a promoção, proteção e recuperação da Saúde, a organização e o funcionamento dos serviços correspondentes, e dá outras providências. Brasília, DF, 1990. 
. INAMPS. Resolução no 258, de 07 de janeiro de 1991. Aprova a Norma Operacional Básica/SUS no 01/91, constante do Anexo I da presente Resolução, que trata da nova política de financiamento do Sistema Único de Saúde - SUS para 1991. Brasília, 1991.

Portaria no 95, de 26 de janeiro de 2001. Norma Operacional da Assistência à Saúde/SUS (NOAS-SUS 01/2001), Brasília, 2001.

. Portaria no. 399/GM de 22 de fevereiro de 2006. Divulga o Pacto pela Saúde 2006. Consolidação do SUS e aprova as Diretrizes Operacionais do Referido Pacto. Brasília, 2006.

. Ministério da Saúde. Regionalização solidária e cooperativa: orientações para sua implementação no SUS. Brasília, 2007. (Série A. Normas e Manuais Técnicos) (Série Pactos pela Saúde; v. 3). Disponível em: <http://portal.saude.gov.br/portal/arquivos/pdf/ volume_3_completo.pdf>. Acesso em: 3 ago. 2013.

Portaria n. 4.279, de 30 de dezembro de 2010. Estabelece diretrizes para a organização da Rede de Atenção à saúde no âmbito do Sistema Único de Saúde (SUS). Brasília, 2010.

Decreto 7.508, de 28 de junho de 2011. Regulamenta a Lei no-8.080, de 19 de setembro de 1990, para dispor sobre a organização do Sistema Único de Saúde - SUS, o planejamento da saúde, a assistência à saúde e a articulação interfederativa, e dá outras providências. Brasília, 2011.

FARIA, R. M.; BORTOLOZZI, A. Espaço, território e saúde: contribuições de Milton Santos para o tema da geografia da saúde no Brasil. RA'E GA - O Espaço Geográfico em Análise, Curitiba, n. 17, p. 31-41, 2009.

FERNANDES, D. Território e territorialidade: algumas contribuições de Raffestin.

Perspectivas em Políticas Públicas, Belo Horizonte, v. 2, n. 4, p. 59-68, jul./dez. 2009.

GADELHA, C. A. G. et al. Saúde e desenvolvimento: uma perspectiva territorial. In: VIANA, A. L. D.; ELIAS, P. E. M. (Org.). Saúde, desenvolvimento e território. São Paulo: HUCITEC, 2009. p. 97-123.

GADELHA, C. A. G. et al. Saúde e territorialização na perspectiva do desenvolvimento. Ciência e Saúde Coletiva, Rio de Janeiro, v. 16, n. 6, Jun. 2011.

GIOVANELLA, L.; MENDONÇA, M. H. M. Atenção Primária à Saúde. In: GIOVANELLA, L. et al. (Org.). Políticas e sistema de saúde no Brasil. Rio de Janeiro: FIOCRUZ, 2008. p. 575626.

GONDIM, G. M. M. et al. O território da saúde: a organização do sistema de saúde e a territorialização. In: BARCELLOS, C. (Org.). Território, ambiente e saúde. Rio de Janeiro: FIOCRUZ, 2008. p. 237-255. 
KOGA, D.; NAKANO, A. K. Perspectivas territoriais e regionais para políticas públicas brasileiras. Serviço Social e Sociedade, São Paulo, n. 85, p. 98-108, 2006.

KOGA, D. Medidas de cidades: entre territórios de vida e territórios vividos. 2. ed. São Paulo: Cortez, 2011.

MENDES, E. V. A construção social da vigilância à saúde do distrito sanitário. Brasília: OPS, 1993. (Série Desenvolvimento de Serviços de Saúde, n. 10, p. 7-19).

2011.

. As redes de atenção à saúde. Brasília: Organização Pan-Americana de Saúde,

MONKEN, M.; BARCELLOS, C. O Território na promoção e vigilância em saúde. In:

FONSECA, A. F. (Org.). O território e o processo saúde-doença. Rio de Janeiro:

EPSJV/Fiocruz, 2007. p. 177-224. Disponível em:

<http://www.epsjv.fiocruz.br/pdtsp/index.php>. Acesso em: 28 fev. 2013.

MONKEN, M. et al. O território na saúde: construindo referências para análises em saúde e ambiente. In: BARCELLOS, C. (Org.) Território ambiente e saúde. Rio de Janeiro:

FIOCRUZ, 2008. p. 23-42.

NAKANO, A. K.; KOGA, D. Os territórios da Urbanidade e a Promoção da Saúde Coletiva. In: SOARES, C. B.; CAMPOS, C. M. S. (Org.). Fundamentos de saúde coletiva e o cuidado de enfermagem. São Paulo: Manole, 2013. p.143-172.

RAFFESTIN, C. Por uma geografia do poder. Tradução de Maria Cecília França. São Paulo: Ática, 1993.

SANTOS, M. Por uma globalização do pensamento único à consciência universal. 4. ed. Rio de Janeiro: Record, 2000.

. O espaço do cidadão. 7. ed. São Paulo: Ed. Universidade de São Paulo, 2007.

SANTOS, L.; ANDRADE, L. O. M. Redes no SUS: marco legal. In: SILVA, S. F. Redes de atenção à saúde: desafios da regionalização no SUS. 2. ed. Campinas: Saberes, 2013. p. 22-34.

SILVEIRA, M. L. Ao território usado a palavra: pensando princípios de solidariedade socioespacial. In: VIANA, A. L. D.; IBAÑEZ, N.; ELIAS, P. E. M. (Org.). Saúde, desenvolvimento e território. São Paulo: Hucitec, 2009. p. 127-150.

SINGER, P. Migrações internas: considerações teóricas sobre o seu estudo. In: MOURA, H. A. (Org.). Migração interna: textos selecionados. Fortaleza: Banco Nordeste do Brasil S.A. (BNB); Escritório Técnico de Estudos Econômicos do Nordeste (ETENE), 1980. 
SILVA, S. F. Requisitos básicos de implantação de redes de atenção à saúde. In: Redes de atenção à saúde: desafios da regionalização do SUS. 2. ed. Campinas: Saberes, 2013. p. 91-117.

VIANA, A. L. D. et al. Novas perspectivas para a regionalização da Saúde. São Paulo em Perspectiva, São Paulo, v. 22, n. 1, p. 92-106, jan./jun. 2008. 